\title{
Characteristics of combustion zone and evolution of mineral phases along bed height in ore sintering
}

\author{
Yao-zu Wang, Jian-liang Zhang, Zheng-jian Liu, Ya-peng Zhang, Dong-hui Liu, and Yi-ran Liu \\ School of Metallurgical and Ecological Engineering, University of Science and Technology Beijing, Beijing 100083, China \\ (Received: 11 December 2016; revised: 14 June 2017; accepted: 15 June 2017)
}

\begin{abstract}
Quantitative parameters of bed combustion, including the thickness of the combustion zone (TCZ), the maximum temperature of the combustion zone (MTCZ), and the bed shrinkage, were characterized through a series of sinter pot tests in transparent quartz pots. The results showed that TCZ first ascended and then descended as the sintering process proceeded. The sintering process was divided into four stages according to the variation rate of the TCZ. A "relative-coordinate" method was developed to obtain the actual reaction temperature of sinter along the height direction. With increasing the sintering temperature, the reactants transformed and entered into liquid phases. The mineral composition and microstructure of the sinter were characterized through X-ray diffraction and scanning electron microscopy-energy-dispersive X-ray spectroscopy. Liquid phases with greater Fe and Al contents were more likely to form acicular-like silico-ferrite of calcium and aluminum after crystallization because of the outward spread of Al, which led to a better fluidity of the liquid. An evolution mechanism of "solid-state reaction — liquid phases formation — crystallization" of the mineral phases is proposed.
\end{abstract}

Keywords: flame front; mineral phases; sintering; evolution mechanism; transparent quartz pots

\section{Introduction}

Sinter, as an important iron-containing raw material for blast furnaces, accounts for more than $70 \%$ of iron-containing raw materials. The output of sinter in China is on the order of hundreds of millions of tons per year [1-3]. Sinter is obtained by mixing together appropriate amounts of iron ore fines, fuel (coke breeze), flux (lime, limestone), and water. The raw material is ignited under negative pressure, resulting in a series of physical and chemical changes [4-6]. The combustion zone $(\mathrm{CZ})$ of sinter is the region where the solid-fuel combustion occurs, which results in an increase of the bed material temperature and the formation of liquid phases. In addition, the thermal decomposition of carbonates and sulfates, as well as the reduction of hematite and other complex oxides, also occurs in CZ [7-8]. The constant negative pressure causes movement of the flame front from top to bottom. As a result, the heat injected from the hot gas preheated by the upper sinter, passes down the bed, raising the ignition temperature of regions ahead of the front. This process is called the self-regenerative function [9]. Furthermore, different reaction temperatures along the bed height modify the liquid volume, the mineral phases, and the metallurgical properties of the sinter, making the sintering an inhomogeneous process [10-12]. Therefore, studies of the characteristics of $\mathrm{CZ}$, including the thickness of the combustion zone (TCZ), the maximum temperature of the combustion zone (MTCZ), the properties of the liquid and solid phases, and the evolution of the sinter phases are important for the controllable preparation of sinter.

Researchers who have previously investigated CZ of sintering have focused mainly on numerical modeling and sinter pot experiments. The results of numerical simulations of the sintering process have already aroused extensive interest. Parker and Hottel [13] proposed a combustion equation for a single carbon particle. Combining Parker and Hottel's equation and the coke combustion rate equation for a quasi-particle, some scholars developed numerical simulation models of the temperature distribution in a sintering layer [14-16]. The quantitative parameters of bed combustion, including the flame front 
speed, duration time in $\mathrm{CZ}$, and the maximum temperature, were simulated through numerical modeling [17-19]. Scholars also used the discrete element method to construct a comprehensive numerical simulation model to describe the structural changes in an iron ore sintering bed [20-21]. Numerical simulations of combustion and heat transfer simulate the homogeneous sintering process well and provide solutions for the quantitative combustion parameters. However, these mathematical models fail to consider the high-temperature behavior of the raw material, the effect of gravity on $\mathrm{CZ}$, and the shrinkage of the bed material, resulting in large discrepancies between the models and the behaviors in real sintering beds.

Sinter pot tests are an indispensable means of reliably studying actual sintering processes. They have been adopted by many investigators. Choudhary and Nandy [22] studied the sinter structure with high-alumina ores at different flame front speeds. Loo and Dukino [11] obtained the maximum temperature, flame front thickness, and residence time using embedded thermocouples in a sintering bed. Loo and Dukino [12] also explored and reported the effect of airflow rate on the flame front parameters and the influence of the average flame front area on the sinter yield and sinter tumble strength. Previous research on CZ has been limited, and the use of steel pot tests with thermocouples to obtain experimental results is less intuitive and is imperfect for investigating CZ. Some sintering studies were creatively carried out in transparent quartz pots, which inspired the present study [23-24].

Here, we establish a research route to characterize the evolution of the flame front and the phase chemistry along the bed height of sintering. Quantitative parameters of bed combustion, including TCZ, MTCZ, and the bed shrinkage, were measured through a series of sinter pot tests in transparent quartz pots with the assistance of an infrared thermometer. A relative-coordinate method was proposed to obtain the actual reaction temperature of sintering in any height direction. The Factsage 6.4 software was used to calculate the amounts and constituents of liquids in different regions of the sinter cake. The phases and microstructure of the sinter were characterized through X-ray diffraction (XRD) and scanning electron microscopy-energy-dispersive X-ray spectroscopy (SEM-EDS); a mechanism for the evolution of the phases was proposed.

\section{Experimental}

\subsection{Properties of raw materials}

Raw materials such as iron ores, fluxes (quick-lime and limestone), sinter return fines, steelmaking slag, and coke breeze were supplied by a Chinese integrated steelwork. The ore blending scheme for laboratory-scale sintering pot tests was similar to that of the sinter plant, with the contents of $\mathrm{Fe}$, $\mathrm{SiO}_{2}$, and $\mathrm{MgO}$ in the sinter maintained at $57.50 \mathrm{wt} \%$, $4.94 \mathrm{wt} \%$, and $1.11 \mathrm{wt} \%$, respectively. The basicity $\left(\mathrm{CaO} / \mathrm{SiO}_{2}\right)$ of the sinter was maintained at 2.00, which was controlled through adjusting the addition of flux. The chemical composition and proportions of the raw materials are listed in Table 1. Table 2 and Table 3 give the ash composition and the proximate analysis results for the coke breeze as well as the constant-volume low calorific value.

\subsection{Description of transparent sintering trials}

Because the temperature of $\mathrm{CZ}$ can (and does) exceed $1300^{\circ} \mathrm{C}$, sintering trials were typically conducted in a steel sinter pot, which rendered the sintering process invisible. Consequently, a substantial amount of important experimental data, such as TCZ, and the movement or migration of the flame front, cannot be directly or accurately measured, which hinders further research into the sintering process. Here sintering trials were conducted in a high-purity quartz tube with a thickness of $5 \mathrm{~mm}$ and a diameter of $150 \mathrm{~mm}$; its schematic is presented in Fig. 1. The height of the sintering

Table 1. Chemical composition and proportions of raw materials

\begin{tabular}{|c|c|c|c|c|c|c|c|}
\hline Material & Total Fe & $\mathrm{SiO}_{2}$ & $\mathrm{Al}_{2} \mathrm{O}_{3}$ & $\mathrm{CaO}$ & $\mathrm{MgO}$ & LOI & Proportion \\
\hline Ore 1 & 56.49 & 5.10 & 1.85 & 9.40 & 1.55 & 0.00 & 8.00 \\
\hline Ore 2 & 57.44 & 5.50 & 1.30 & 0.25 & 0.31 & 10.50 & 9.88 \\
\hline Ore 3 & 61.98 & 5.19 & 2.06 & 0.21 & 0.23 & 2.10 & 3.95 \\
\hline Ore 4 & 65.22 & 2.41 & 1.40 & 0.21 & 0.29 & 2.50 & 19.77 \\
\hline Ore 5 & 62.37 & 4.70 & 2.35 & 0.21 & 0.25 & 3.80 & 19.77 \\
\hline Sinter return fines & 57.90 & 5.02 & 1.88 & 10.01 & 1.30 & - & 24.00 \\
\hline Steelmaking slag & 21.05 & 12.37 & 3.81 & 38.98 & 8.74 & 1.10 & 2.63 \\
\hline Quick-lime & - & 1.41 & 0.33 & 75.00 & 2.29 & 20.62 & 1.50 \\
\hline Limestone & - & 3.00 & 0.00 & 49.50 & 4.00 & 41.40 & 1.52 \\
\hline
\end{tabular}


Table 2. Ash composition and proportion of coke breeze wt $\%$

\begin{tabular}{cccccccc}
\hline \multicolumn{7}{c}{ Ash composition } & \\
\cline { 1 - 6 } $\mathrm{SiO}_{2}$ & $\mathrm{Al}_{2} \mathrm{O}_{3}$ & $\mathrm{CaO}$ & $\mathrm{MgO}$ & $\mathrm{Fe}_{2} \mathrm{O}_{3}$ & $\mathrm{SO}_{2}$ & $\mathrm{P}$ & \\
\hline 45.00 & 30.00 & 4.00 & 0.60 & 15.4 & 4.49 & 0.51 & 4.00 \\
\hline
\end{tabular}

Table 3. Proximate analysis of coke breeze and the constant-volume low calorific value

\begin{tabular}{ccccc}
\hline \multicolumn{4}{c}{ Proximate analysis $/ \mathrm{wt} \%$} & \multirow{2}{*}{$Q_{\text {net, v, ad }} /\left(\mathrm{kJ}^{\prime} \cdot \mathrm{kg}^{-1}\right)$} \\
\cline { 1 - 4 } Ad & $\mathrm{Vd}$ & $\mathrm{FCd}$ & $\mathrm{Mad}$ & \\
\cline { 1 - 4 } 10.19 & 9.88 & 79.29 & 0.64 & 26189.68 \\
\hline
\end{tabular}

Note: Ad—ash component; Vd-volatile component; FCd—fixed carbon content; Mad - the moisture of the coal sample; $Q_{\text {net, v, ad }}-$ low calorific capacity of coal.

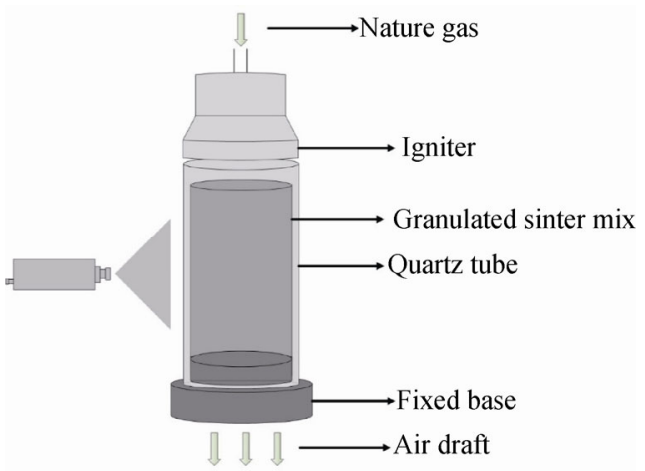

Fig. 1. Schematic of the visual sinter pot.

material layer was $800 \mathrm{~mm}$. The sintering temperature was measured using an infrared thermometer (DT-8869h) with a measurement range from 800 to $2200^{\circ} \mathrm{C}$ and an accuracy of $1^{\circ} \mathrm{C}$. A fixed ruler was used to measure the height of the soft melting layer, and the whole process of the experiments was recorded with a high-definition video camera.

In a typical procedure, raw materials were thoroughly blended manually according to the blending scheme and some water was added. After a quick-aging, the mixture was transferred into a drum of $500 \mathrm{~mm}$ long and $200 \mathrm{~mm}$ in diameter for granulation for $3 \mathrm{~min}$ at a rotation speed of 17 $\mathrm{r} / \mathrm{min}$. $2 \mathrm{~kg}$ of sinter with the particle size range between 10 and $12.5 \mathrm{~mm}$ was introduced into the sinter pot as the bedding material. When the granulation was finished, the mix was charged and ignited at a temperature of $(1050 \pm 50)^{\circ} \mathrm{C}$ for $1.5 \mathrm{~min}$ with a suction pressure of $6 \mathrm{kPa}$. A suction pressure of $10 \mathrm{kPa}$ was maintained during the sintering process. As shown in Fig. 2, the sinter cake was equally divided into six parts for studying the evolution of the mineragraphy of the sinter cake in the height direction. The samples were crushed and sieved to grain sizes from 10 to $12.5 \mathrm{~mm}$ before subsequent experiments. The average of three groups of repeated trials was reported as the results of the experiment.

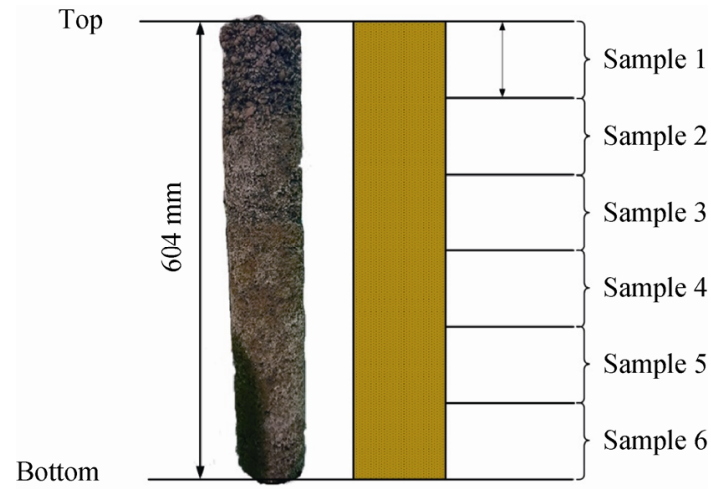

Fig. 2. Schematic of the sampling of sinter after reaction.

\subsection{Characterization of sintered samples}

The microstructures of samples were observed using a Quanta 250 environmental scanning electron microscope. In addition, the mineral compositions of the obtained sinter were characterized by EDS. The powdered samples were characterized by XRD using $\mathrm{Cu} \mathrm{K}_{\alpha}$ radiation (M21XVHF22, MAC Science Co., Ltd., Japan).

\section{Results and discussion}

\subsection{Migration behavior of $\mathrm{CZ}$}

The migration of $\mathrm{CZ}$ and bed shrinkage during the sintering process are complicated processes that are not only dependent on the heat generated from the combustion of the coke particles but also on the properties of the raw material, moisture content, airflow rate, and the thickness of the feed layer. Loo and Dukino [10-12] have reported a method to determine the bed temperature using thermocouples. To effectively overcome the technical difficulties brought about by thermocouples, we instead used infrared thermometry in this study. The $\mathrm{CZ}$ was defined as the region where the sintering temperature was greater than $1000^{\circ} \mathrm{C}$. Images of the actual sintering process in a transparent quartz pot with a height of $800 \mathrm{~mm}$ are shown in Fig. 3. In the pattern, the variation of TCZ and the bed shrinkage are clearly observed; the detailed statistical results are displayed in Fig. 4. The results show that the TCZ first ascended and then descended as the sintering process proceeded. The sintering process can be divided into four stages according to the variation rate of the TCZ. Stage 1 is the ignition period, where the combustion of natural gas and coke breeze releases large amounts of heat, leading to an increase in bed temperature, a rapid increase of the TCZ within $3 \mathrm{~min}$, and a sharp increase in the temperature of the exhaust gas. Stage 2 is the post-ignition period, where the energy mainly 
originates from the combustion of coke breeze and from the self-regenerative function; the heat released in this stage slightly exceeds that released in stage 1 [25-26]. Compared with that of stage 1 , the TCZ of stage 2 increased slowly from 65 to $80 \mathrm{~mm}$ between the sintering time of 3 and 16 min. Stage 3 is the period of rapid increase of the TCZ. Because of the energy accumulation during the early sintering process, the self-regenerative function becomes increasingly significant, accompanied by a rapid increase of the TCZ. At $23 \mathrm{~min}$, the TCZ and the bed shrinkage reached their respective maxima simultaneously. At this point, $\mathrm{CZ}$ migrated to the bottom of the bed (Fig. 3). In stage 4, which occurs toward the end of the sintering process, the bed shrinkage remains unchanged, with a final shrinkage of $190 \mathrm{~mm}$. A noticeable descent of the TCZ and a dramatic increase of the temperature of the sintering exhaust gas during this period (Fig. 4) indicate that the sintering was finished.
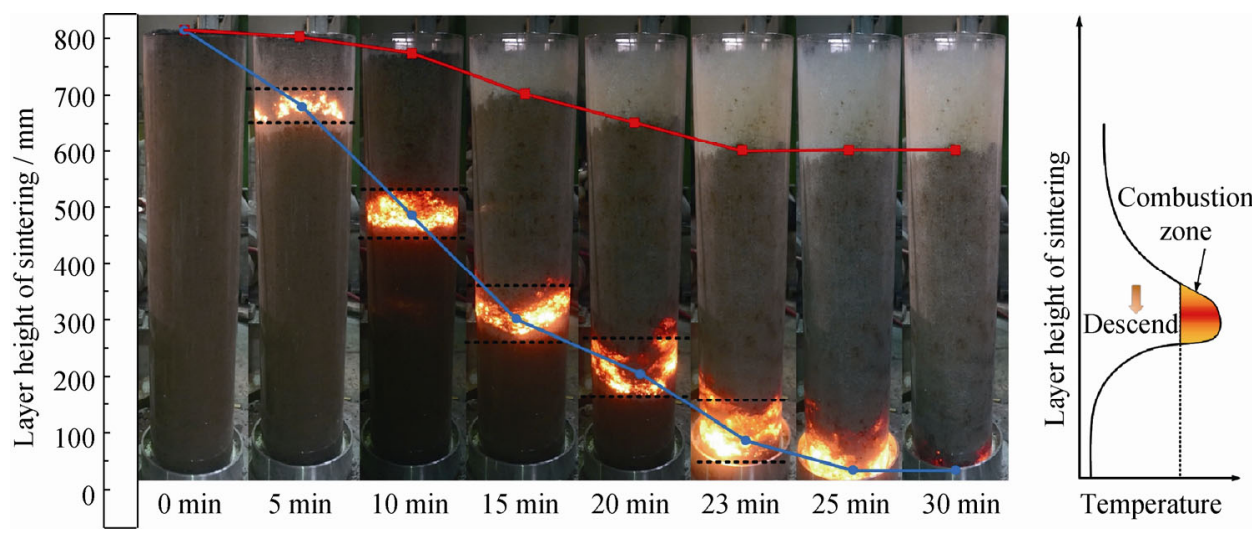

Fig. 3. Images of the actual sintering process.

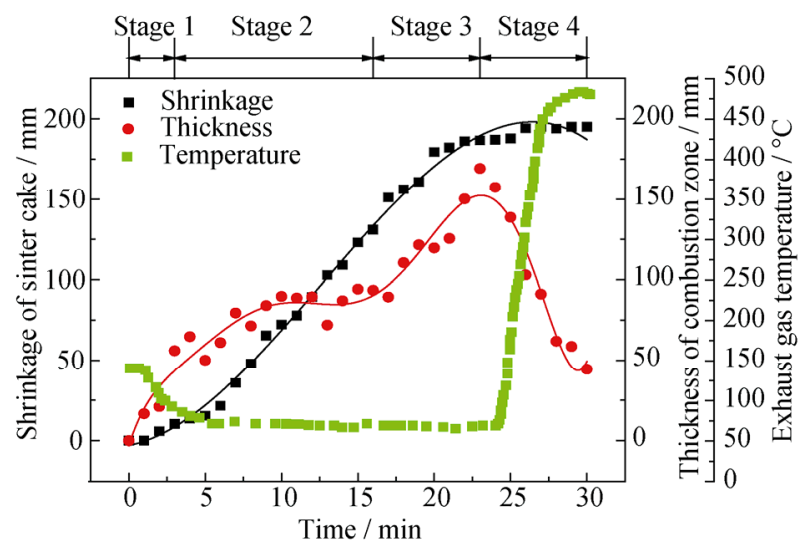

Fig. 4. Variation of the sinter cake shrinkage, the thickness of the combustion zone (TCZ), and the exhaust gas temperature as functions of sintering time.

The self-regenerative function along the bed height is known to modify the liquid volume, mineral phases, and the metallurgical properties of the sinter, making the sintering an inhomogeneous process. Therefore, confirming the maximum temperature of $\mathrm{CZ}$ of sinter cake is vital to establish the corresponding relation between the sintering temperature and the properties of the sinter. Such research is relatively infrequent because bed shrinkage during the sintering process makes the measurement of combustion difficult.

We developed a method to establish the sintering temper- ature distribution for the sinter cake in the height direction. The thickness of the sinter material bed was $800 \mathrm{~mm}$, and the height of the sinter cake was $604 \mathrm{~mm}$. If the top of the sinter cake is taken as the original point, the distance from the center of $\mathrm{CZ}$ to the original point (DFCO) can be recorded together with the sintering temperature as a function of sintering time (Fig. 5). As shown in Fig. 5, the center of $\mathrm{CZ}$ descended as the reaction progressed and reached the bottom of the sinter cake at $23 \mathrm{~min}$. The results indicated that MTCZ increased from 1175 to $1409^{\circ} \mathrm{C}$ during sintering, as shown in Fig. 5. Combining the variation of the MTCZ and the DFCO with sintering time, we obtained the sintering temperature distribution for the sinter cake in the height direction, as shown in Fig. 6. To further study the sinter, the sinter cake was divided into six parts (Fig. 2) and the sintering temperature of each part was approximated on the basis of the integral mid-value through the following equation:

$\bar{T}=\frac{\int_{\tau_{0}}^{\tau} T d \tau}{\tau-\tau_{0}}$

where $T$ is the sintering temperature measured by the infrared thermometer, $\tau$ is the sintering time, and the calculated integral mid-values $(\bar{T})$ is defined as the sintering temperature of each sinter part (1-6). The red points in Fig. 6 are the calculated $\bar{T}$. 


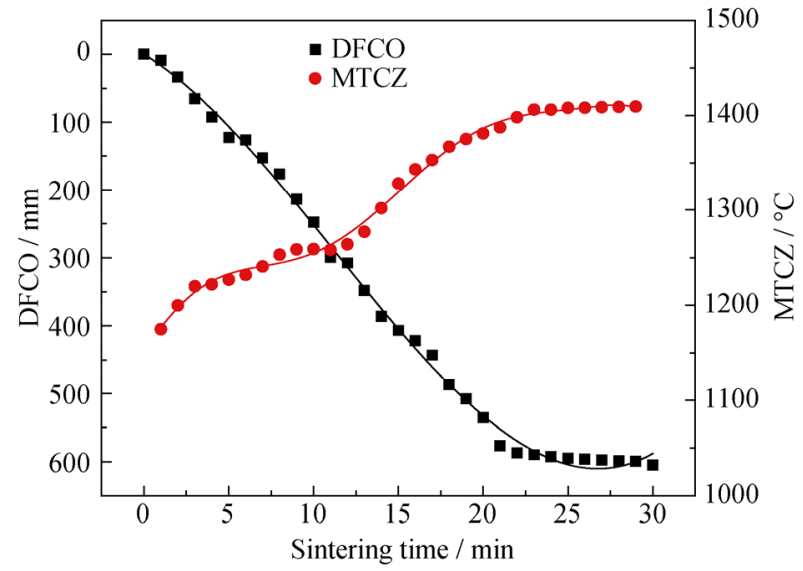

Fig. 5. Variation of the MTCZ and DFCO with sintering time.

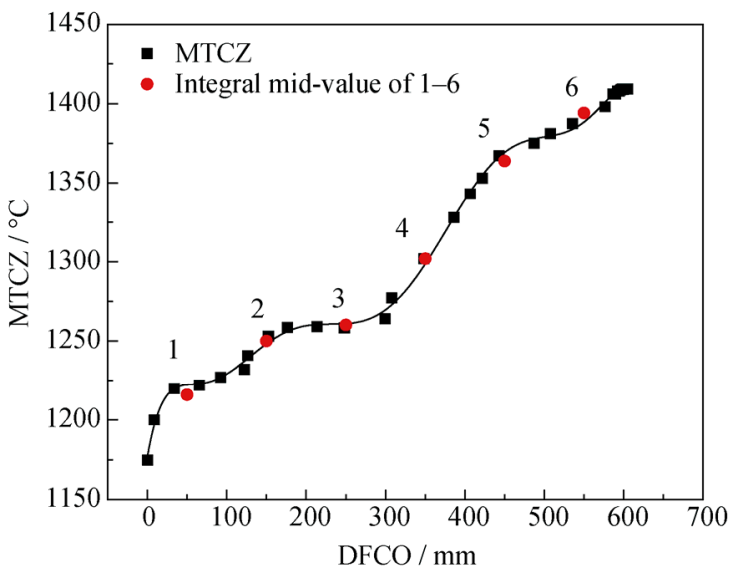

Fig. 6. Maximum sintering temperature distribution of the sinter cake in the height direction.

\subsection{Phases transformation and microstructure observa- tion}

\subsubsection{Microstructure observation}

To compare the phase transformations of the sinter cake along the height direction, XRD patterns of sinters 1-6 are presented in Fig. 7. The key phases of iron oxide- hematite, silico-ferrite of calcium and aluminum (SFCA) (SFCA- $\mathrm{M}_{14} \mathrm{O}_{20}$, SFCA-I- $\mathrm{M}_{20} \mathrm{O}_{28}$, and SFCA-II- $\mathrm{M}_{34} \mathrm{O}_{48}$ ), and magnetite, are marked in the patterns. With increasing sintering temperature, the peaks of the SFCA phases gradually decreased in intensity and those of hematite and magnetite increased in intensity, which indicates that sintering at a temperature greater than $1300^{\circ} \mathrm{C}$ provided no advantage for the formation of SFCA; these results are consistent with those of previous studies [27-28]. Notably, sample 1 exhibited a phase transformation from hematite to SFCA at temperature less than $1250^{\circ} \mathrm{C}$. Furthermore, the best temperatures for the formation of SFCA were 1250 and $1260^{\circ} \mathrm{C}$.

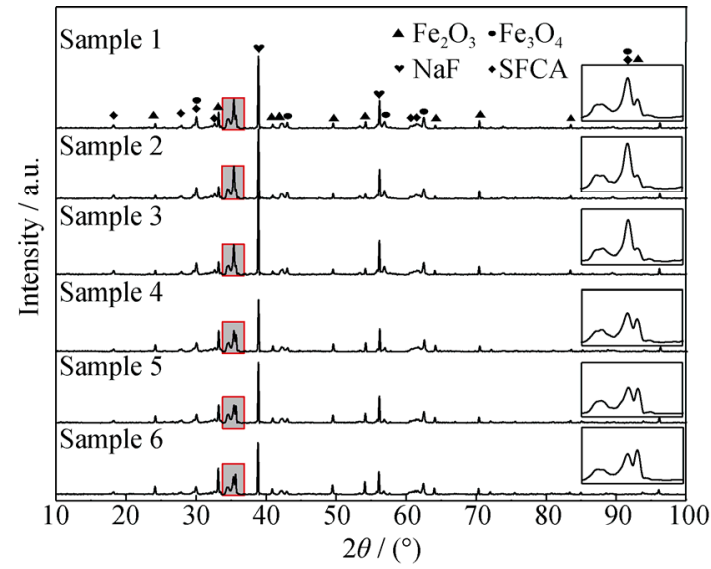

Fig. 7. XRD patterns of sinter along the height of the bed.

Typical microstructures of sinter samples 1-6, as observed by SEM, are shown in Fig. 8. Labels A, B, and C in Fig. 8 indicate low-, medium-, and high-magnification images of the sinter, respectively. As evident in the figure, the porosity of the sinter was gradually reduced from sample 1 to sample 6. Pores in the sinter were mainly derived from the gaps between the material particles, the combustion of fixed carbon, the evaporation of moisture and crystal water, and the contraction of the solid--melt assemblage [29]. In the process of sintering, the mass of liquid increased at the bottom of the sinter cake because of the high sintering temperature, which is verified in a later section. Because of the action of gravity of the upper sintered zone, CZ was compressed and the liquid enhanced the densification by filling the voids.

As shown in Figs. 8(1-B), 8(2-B), and 8(2-C), a mass of acicular-like calcium ferrite (ACF) was found. The ACF, which possess better strength and reducibility than the non-acicular SFCA, was the key component. Compared with the ACF of sample 2, the ACF of sample 1 was slender, with a diameter of $1.4 \mu \mathrm{m}$ and a length of $60 \mu \mathrm{m}$, which indicates that the crystallization was imperfect at $1216^{\circ} \mathrm{C}$. In addition, much of the skeletal hematite $(\mathrm{SH})$ was found around the pores, with a morphology of fishbone-like features connected by parallel crystals, as shown in Fig. 8(1-C). A number of other authors [30-32] have reported that volume expansion will occur during the reduction of this kind of SH, which would adversely affect the low-temperature reduction disintegration of sinter. This volume expansion is mainly due to the rapid cooling of the surface of the sinter cake making the transition of the $\mathrm{Fe}_{2} \mathrm{O}_{3}$ phase incomplete. However, at $1250^{\circ} \mathrm{C}$ in Figs. $8(2-\mathrm{B})$ and $8(2-\mathrm{C})$, ACF was well crystallized, with a fascinating dendritic morphology. 


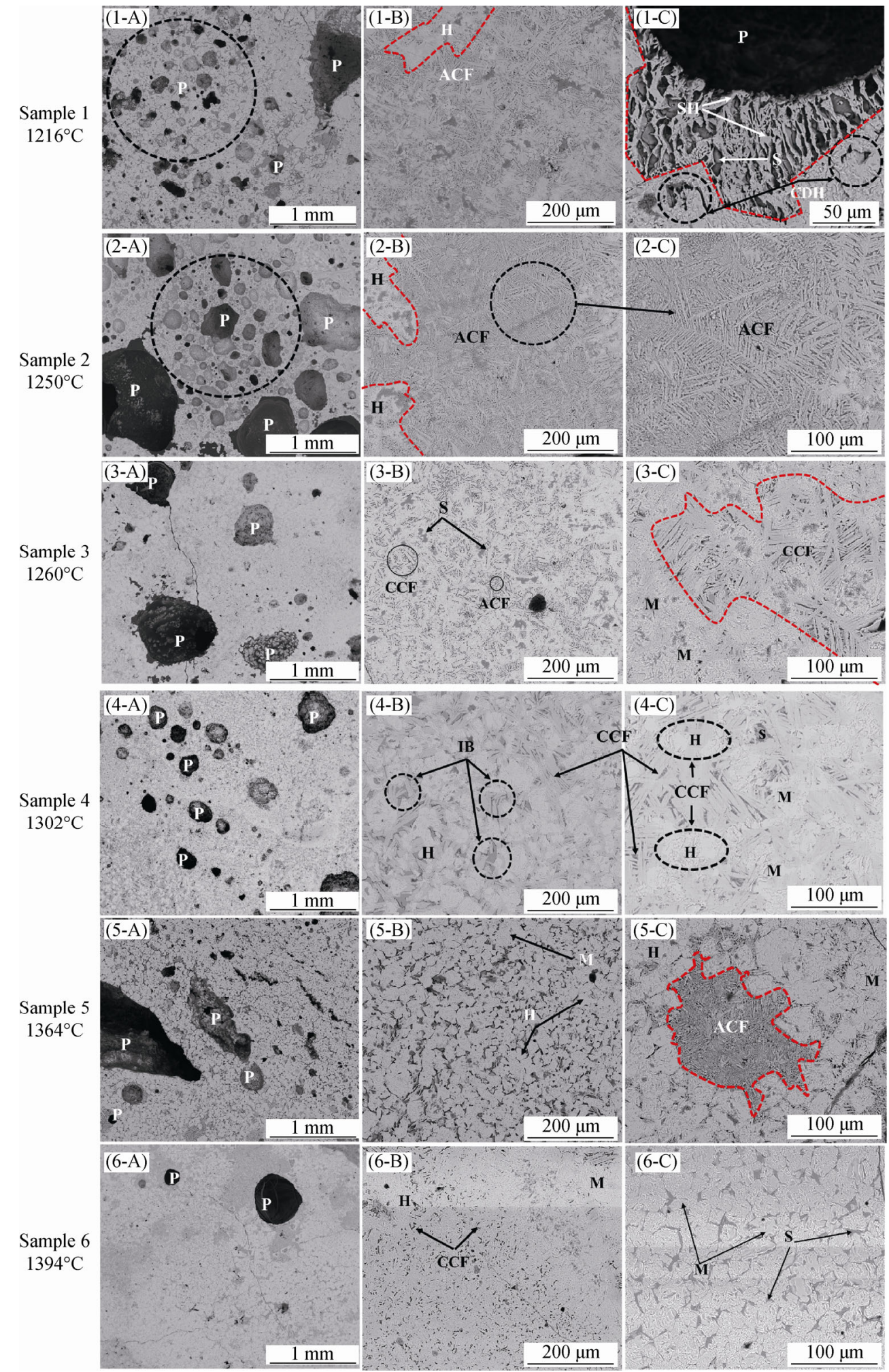

Fig. 8. Microstructure of sinter samples 1-6 along the sinter cake: P-pore; H-hematite; ACF-acicular-like calcium ferrite; SH-skeletal hematite; CDH-crystal defect of hematite; S-silicate; CCF-columnar-like calcium ferrite; IB-interphase boundary; M-magnetite.

The SFCA of sample 3, which was sintered at $1260^{\circ} \mathrm{C}$, shows the coexistence of ACF and columnar-like calcium ferrite (CCF). The $\mathrm{CCF}$ of sample 3, with an average diameter of $12.5 \mu \mathrm{m}$ and an average length of $160.8 \mu \mathrm{m}$, is 
another SFCA with a low Fe content. Some of the SFCA in sample 3 retained the dendritic structure with a small amount of acicular calcium ferrite, indicating that an increase of the sintering temperature would lead to the transformation of ACF to CCF. As shown in Figs. 8(4-B) and $8(4-\mathrm{C})$, the SFCA of sample 4 exhibited the columnar microstructure, whereas the dendritic structure was absent. The SFCA content of sample 4 was significantly lower than that of samples 1-3. The CCF crystallized at the boundary of iron oxide (hematite, magnetite) and slag, which indicates that hematite provides $\mathrm{Fe}_{2} \mathrm{O}_{3}$ and silicate provides elements such as $\mathrm{Si}, \mathrm{Al}$, and $\mathrm{Ca}$ in the $\mathrm{CCF}$ crystallization process. Figs. 8(5-B) and 8(5-C) show the microstructure of sample 5 , which was sintered at a higher temperature of $1364^{\circ} \mathrm{C}$; interconnected crystals of $\mathrm{Fe}_{2} \mathrm{O}_{3}$ are formed because of the soft melting of $\mathrm{Fe}_{2} \mathrm{O}_{3}$. More importantly, the content of magnetite gradually increased because of the decomposition of $\mathrm{Fe}_{2} \mathrm{O}_{3}$ at temperatures above $1300^{\circ} \mathrm{C}$, with a decreased level of SFCA. Interestingly, a small quantity of ACF was found in the gap of $\mathrm{Fe}_{2} \mathrm{O}_{3}$ interconnected crystals. Figs. 8(6-B) and (6-C) show the SEM images of sample 6, which was collected from the bottom of the sinter cake; the images show a large quantity of magnetite and a small amount of SFCA.

3.2.2. Thermodynamic analysis of phase transformation using Factsage 6.4

The mass fractions of the liquid phases of sinter under 1216- $1394^{\circ} \mathrm{C}$ were calculated through Factsage 6.4 using the Equilib and Phase Diagram modules. The main databases were FToxid-SLAGA, FToxid-SPINA, and FToxid-CORU. To reduce the complexity and improve the accuracy of the analysis, only the major components of the sinter were considered during the calculation. The chemical constituents were determined by chemical analysis and X-ray fluorescence analysis. With respect to the forms of $\mathrm{Fe}$ in the raw material, all forms were converted to the form of $\mathrm{Fe}_{2} \mathrm{O}_{3}$ and $\mathrm{Fe}_{3} \mathrm{O}_{4}$ in accordance with the proportion of total $\mathrm{Fe}$ and $\mathrm{FeO}$. All the oxides were normalized as shown in Table 4. The thermodynamic calculation results for the liquid phase in the sintering process are shown in Fig. 9. The results show that the mass fraction of liquid phase increased from $12.9 \%$ to $62.85 \%$ as the sintering temperature was increased from 1216 to $1394^{\circ} \mathrm{C}$, which indicates that more liquid phase would be produced at the bottom of the sinter cake.

Table 4. Composition of the raw material

\begin{tabular}{|c|c|c|c|c|c|c|}
\hline \multicolumn{6}{|c|}{ Composition / wt $\%$} & \multirow{2}{*}{$R$} \\
\hline $\mathrm{Fe}_{2} \mathrm{O}_{3}$ & $\mathrm{Fe}_{3} \mathrm{O}_{4}$ & $\mathrm{CaO}$ & $\mathrm{SiO}_{2}$ & $\mathrm{Al}_{2} \mathrm{O}_{3}$ & $\mathrm{MgO}$ & \\
\hline 78.14 & 3.88 & 9.88 & 4.94 & 2.06 & 1.11 & 2.00 \\
\hline
\end{tabular}

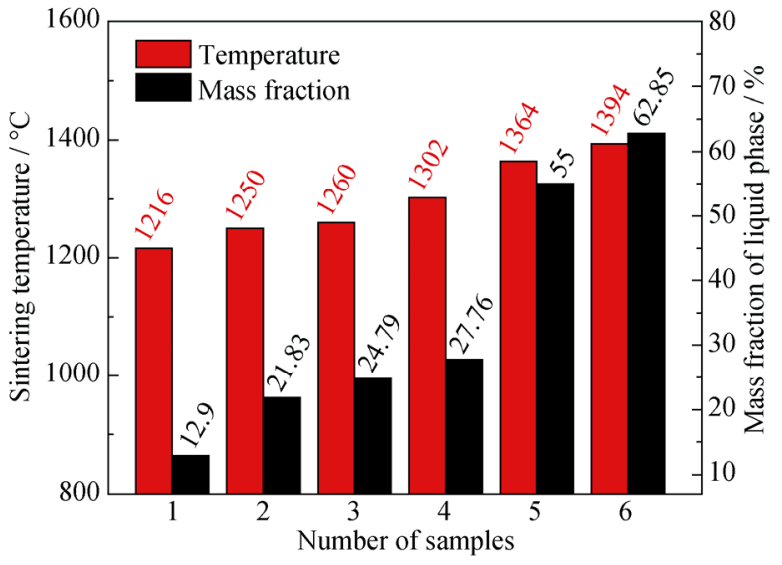

Fig. 9. Mass fraction of liquid phase versus sintering temperature.

\subsection{Phase evolution mechanism of sinter cake}

The literature contains a large number of reports of studies of sinter phases, especially studies of SFCA. The formation sequence of phases was proposed by using tablet samples [33-34]. The phase evolution of SFCA in sinter mixture was characterized through a series of in situ XRD and heat/quench experiments, improving understanding of the effect of oxygen partial pressure that may maximize the formation of SFCA in industrial sintering processes [27,35-37]. Loo and Leung [38] reported the influence of phosphorus, basicity, silica level, maximum sintering temperature, and gangue level on the bonding phase structure of sinters. Choudhary [39] indicated the reaction sequences and formation of phases in sinter using a 400-mm test pot. In the case of the formation mechanism of SFCA, Webster et al. [40] and Ding and Guo [41] have extensively researched the formation of calcium ferrite in sinter. On the basis of these previous studies, an evolution mechanism involving "solid-state reaction-liquid phase formation-crystallization" of the mineral phase of high-hematite iron ores was proposed through quartz sintering pot texts and thermodynamic calculations, as shown in Fig. 10. The initial liquid phase contained more $\mathrm{Fe}$ and $\mathrm{Al}$. The liquid phase was more likely to form ACF after crystallization because of the outward spread of Al, which led to better fluidity of the liquid. Therefore, ACF was easier to generate during low-temperature sintering (Figs. 10(c), 10(d), and 10(e)). With an increase of sintering temperature, the $\mathrm{SiO}_{2}$ content of the liquid phase increased. The affinity of $\mathrm{CaO} \cdot \mathrm{SiO}_{2}$ was stronger than that of $\mathrm{CaO} \cdot \mathrm{Fe}_{2} \mathrm{O}_{3}$, which led to a decrease in SFCA content. Liquid with more $\mathrm{Si}$ and $\mathrm{Al}$ would increase the viscosity, which is likely to be CCF after crystallization (Figs. 10(e) and 10(f)). As shown in Figs. $10(\mathrm{~g})$ and $10(\mathrm{~h}), \mathrm{Fe}_{2} \mathrm{O}_{3}$ will decompose with the further increase in sintering temperature. 


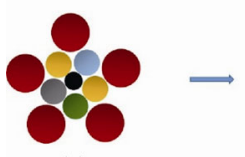

(a)
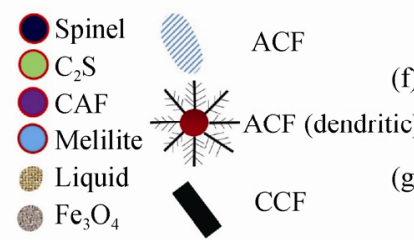

(c)

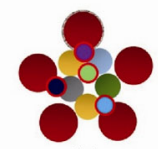

(b)

(d)

(e)

(g)

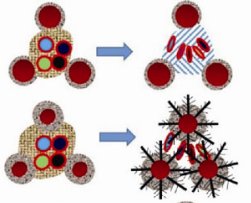

)

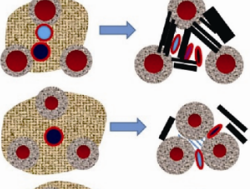

(h)

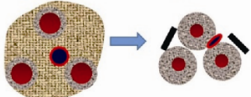

Fig. 10. Mineral evolution of the sintering process along the bed height: (a) before sintering; (b) solid-phase reaction; (c) mineral of sample 1; (d) mineral of sample 2; (e) mineral of sample 3; (f) mineral of sample 4; (g) mineral of sample 5; (h) mineral of sample 6 .

\section{Conclusions}

A research route of "combustion zone-liquid and solid phase of sinter - evolution of mineral phase" was established to characterize the evolution of the flame front and the mineral phases along the bed height of sintering.

(1) Quantitative parameters of the bed combustion, including TCZ, MTCZ, and the bed shrinkage were measured. The TCZ first increased and then decreased as the sintering process proceeded. The sintering process was divided into four stages according to the variation rate of TCZ.

(2) Notably, sample 1 exhibited a phase transformation from hematite to SFCA at temperature less than $1250^{\circ} \mathrm{C}$. Sintering at a temperature greater than $1300^{\circ} \mathrm{C}$ provided no advantage for the formation of SFCA.

(3) The initial liquid phase contained more $\mathrm{Fe}$ and $\mathrm{Al}$. The liquid phase was more likely to form ACF after crystallization because of the outward spread of $\mathrm{Al}$, which led to a better fluidity of the liquid. With increasing sintering temperature, the $\mathrm{SiO}_{2}$ content of the liquid phase increased, which led to a decrease of SFCA content.

\section{Acknowledgements}

This work was financially supported by the National Science Foundation for Young Scientists of China (No. 51304014).

Open Access This article is distributed under the terms of the Creative Commons Attribution 4.0 International License (http://creativecommons.org/licenses/by/4.0/), which permits unrestricted use, distribution, and reproduction in any medium, provided you give appropriate credit to the original author(s) and the source, provide a link to the Creative Commons license, and indicate if changes were made.

\section{References}

[1] X. Gao, Development situation and trend analysis of sintering industry in China, Iron Steel, 43(2008), No. 1, p. 85.

[2] H.F. Wang, Y.D. Pei, C.X. Zhang, and Z.X. Zhao, Green development of sintering/pellet procedure in China iron and steel industry, Iron Steel, 51(2016), No. 1, p. 1.

[3] S.L. Wu, D.J. Wang, and L. Li, Technological innovation of the contemporary large-scale sintering, Iron Steel, 47(2012), No. 9, p. 1.

[4] N.V.Y. Scarlett, M.I. Pownceby, I.C. Madsen, and A.N. Christensen, Reaction sequences in the formation of silico-ferrites of calcium and aluminum in iron ore sinter, Metall. Mater. Trans. B, 35(2004), No. 5, p. 929.

[5] F. Patisson, J.P. Bellot, D. Ablitzer, E. Marlière, C. Dulcy, and J.M. Steiler, Mathematical modeling of iron ore sintering process, Ironmaking Steelmaking, 18(1991), No. 2, p. 89.

[6] L.H. Hsieh and J.A. Whiteman, Sintering conditions for simulating the formation of mineral phases in industrial iron ore sinter, ISIJ Int., 29(1989), No. 1, p. 24.

[7] R.R. Lovel, K.R. Vining, and M. Dell'amico, The influence of fuel reactivity on iron ore sintering, ISIJ Int., 49(2009), No. 2, p. 195.

[8] M.I. Pownceby and J.M.F. Clout, Phase relations in the Fe-rich part of the system $\mathrm{Fe}_{2} \mathrm{O}_{3}-\left(\mathrm{Fe}_{3} \mathrm{O}_{4}\right)-\mathrm{CaO}-\mathrm{SiO}_{2}$ at $1240-1300^{\circ} \mathrm{C}$ and oxygen partial pressure of $5 \times 10^{-3} \mathrm{~atm}$ : implications for iron ore sinter, Miner. Process. Extr. Metall., 109(2000), No. 1, p. 36.

[9] Y.P. Zhang, J.L. Zhang, C. Zhang, Y.Z. Wang, Z.J. Liu, G.W. Wang, and Z.X. Zhao, Modelling and visual verification of combustion zone transfer in ultra-thick bed sintering process, Ironmaking Steelmaking, 44(2016), No. 4, p. 1.

[10] C.E. Loo and R.D. Dukino, Laboratory iron ore sintering studies. 1. Process simulation and airflow rate, Miner. Process. Extr. Metall., 123(2014), No. 4, p. 191.

[11] C.E. Loo and R.D. Dukino, Laboratory iron ore sintering studies. 2. Quantifying flame front properties, Miner. Process. Extr. Metall., 123(2014), No. 4, p. 197.

[12] C.E. Loo and R.D. Dukino, Laboratory iron ore sintering studies. 3. Critical heat transfer period, Miner. Process. Extr. Metall., 123(2014), No. 4, p. 204.

[13] A.S. Parker and H.C. Hottel, Combustion rate of carbon: Study of gas-film structure by microsampling, Ind. Eng. Chem., 28(1936), No. 11, p. 1334.

[14] K.I. Ohno, K. Noda, K. Nishioka, T. Maeda, and M. Shimizu, Effect of coke combustion rate equation on numerical simulation of temperature distribution in iron ore sintering process, ISIJ Int., 53(2013), No. 9, p. 1642. 
[15] R.W. Young, Dynamic mathematical model of sintering process, Ironmaking Steelmaking, 4(1977), No. 5, p. 321.

[16] W. Yang, C. Ryu, S. Choi, E. Choi, D. Lee, and W. Huh, Modeling of combustion and heat transfer in an iron ore sintering bed with considerations of multiple solid phases, ISIJ Int., 44 (2004), No. 3, p. 492.

[17] J.A. de Castro, N. Nath, A.B. Franca, V.S. Guilherme, and Y. Sasaki, Analysis by multiphase multicomponent model of iron ore sintering based on alternative steelworks gaseous fuels, Ironmaking Steelmaking, 39(2012), No. 8, p. 605.

[18] B.K. Giri and G.G. Roy, Mathematical modelling of iron ore sintering process using genetic algorithm, Ironmaking Steelmaking, 39(2012), No. 1, p. 59.

[19] J. Mitterlehner, G. Löffler, F. Winter, H. Hofbauer, H. Schmid, E. Zwittag, T.H. Buergler, O. Pammer, and H. Stiasny, Modeling and simulation of heat front propagation in the iron ore sintering process, ISIJ Int., 44(2004), No. 1, p. 11.

[20] M.V. Ramos, E. Kasai, J. Kano, and T. Nakamura, Numerical simulation model of the iron ore sintering process directly describing the agglomeration phenomenon of granules in the packed bed, ISIJ Int., 40(2000), No. 5, p. 448.

[21] P.A. Cundall and O.D.L. Strack, A discrete numerical model for granular assemblies, Géotechnique, 29(1979), No. 1, p. 47.

[22] M.K. Choudhary and B. Nandy, Effect of flame front speed on sinter structure of high alumina iron ores, ISIJ Int., 46(2006), No. 4, p. 611.

[23] P. Hou, S. Choi, E. Choi, and H. Kang, Improved distribution of fuel particles in iron ore sintering process, Ironmaking Steelmaking, 38(2011), No. 5, p. 379.

[24] G.S. Feng, S.L. Wu, and Z.J. Zhao. Research on improving hot permeability of deep bed sintering, Sintering Pelletizing, 36(2011), No. 1, p. 1.

[25] W. Yang, S. Choi, E.S. Choi, D.W. Ri, and S. Kim, Combustion characteristics in an iron ore sintering bed-evaluation of fuel substitution, Combust. Flame, 145(2006), No. 3, p. 447.

[26] T. Kawaguchi, S. Sato, and K. Takata, Development and application of an integrated simulation model for iron ore sintering, Tetsu-to-Hagane, 73(1987), No. 4, p. 1940.

[27] N.V.Y. Scarlett, I.C. Madsen, M.I. Pownceby, and A.N. Christensen, In situ X-ray diffraction analysis of iron ore sinter phases, J. Appl. Crystallogr., 37(2004), No. 3, p. 362.

[28] N. Taguchi, T. Otomo, and K. Tasaka, Effect of $\mathrm{SiO}_{2}$ and $\mathrm{Al}_{2} \mathrm{O}_{3}$ additions on the reduction and resultant expansion of synthetic materials in the vicinity of $\mathrm{CaO} \cdot 2 \mathrm{Fe}_{2} \mathrm{O}_{3}$ composition, Tetsu-to-Hagane, 73(1987), No. 15, p. 1885.
[29] Y.H. Yang and N. Standish, Fundamental mechanisms of pore formation in iron ore sinter and pellets, ISIJ Int., 31(1991), No. 5, p. 468.

[30] I. Shigaki, M. Sawada, and N. Gennai, Increase in low-temperature reduction degradation of iron ore sinter due to hematite alumina solid solution and columnar calcium ferrite, ISIJ Int., 26(1986), No. 6, p. 503.

[31] I. Shigaki, M. Sawada, M. Maekawa, and K. Narita, Fundamental study of size degradation mechanism of agglomerates during reduction, ISIJ Int., 22(1982), No. 11, p. 838.

[32] M. Asada, M. Shima, and Y. Omori, Measurement of macro strain in the course of reduction of the skeletal hematite in sinter, Tetsu-to-Hagane, 73(1987), No. 15, p. 1901.

[33] L.H. Hsieh and J.A. Whiteman, Effect of raw material composition on the mineral phases in lime-fluxed iron ore sinter, ISIJ Int., 33(1993), No. 4, p. 462.

[34] F. Matsuno and T. Harada, Changes of mineral phases during the sintering of iron ore-lime stone systems, ISIJ Int., 21(1981), No. 5, p. 318.

[35] N.A.S. Webster, M.I. Pownceby, I.C. Madsen, and J.A. Kimpton, Effect of oxygen partial pressure on the formation mechanisms of complex Ca-rich ferrites, ISIJ Int., 53(2013), No. 5, p. 774.

[36] N.A.S. Webster, M.I. Pownceby, and I.C. Madsen, In situ $\mathrm{X}$-ray diffraction investigation of the formation mechanisms of silico-ferrite of calcium and aluminium-I-type (SFCA-I-type) complex calcium ferrites, ISIJ Int., 53(2013), No. 8, p. 1334.

[37] N.A.S. Webster, M.I. Pownceby, I.C. Madsen, and J.A. Kimpton, Silico-ferrite of calcium and aluminum (SFCA) iron ore sinter bonding phases: new insights into their formation during heating and cooling, Metall. Mater. Trans. B, 43(2012), No. 6, p. 1344.

[38] C.E. Loo and W. Leung, Factors influencing the bonding phase structure of iron ore sinters, ISIJ Int., 43(2003), No. 9, p. 1393.

[39] M.K. Choudhary, Evolution of sinter structure along bed height of quenched test pot, ISIJ Int., 47(2007), No. 3, p. 516.

[40] N.A.S. Webster, M.I. Pownceby, I.C. Madsen, A.J. Studer, J.R. Manuel, and J.A. Kimpton, Fundamentals of silico-ferrite of calcium and aluminum (SFCA) and SFCA-I iron ore sinter bonding phase formation: effects of $\mathrm{CaO}: \mathrm{SiO}_{2}$ ratio, Metall. Mater. Trans. B, 45(2014), No. 6, p. 2097.

[41] X. Ding and X.M. Guo, The formation process of silico-ferrite of calcium (SFC) from binary calcium ferrite, Metall. Mater. Trans. B, 45(2014), No. 4, p. 1221. 